\title{
125 YEARS \\ 125 years of developments in \\ dentistry, 1880-2005 \\ Part 1: British dental and other journals
}

\section{S. Gelbier 1}

\section{INTRODUCTION}

This series of seven articles demonstrates how some aspects of dentistry have progressed since 1880 when the Monthly Review of Dental Surgery became the Journal of the British Dental Association, to renaming as the British Dental Journal in 1903, right up to 2005.

During those years the profession, manufacturers and other traders played important roles in the development of dentistry. Early improvements came as the profession developed, with the need for education, training, qualifications and dental periodicals. Many associated developments in techniques, equipment, materials and the ways in which services were delivered were made possible because of the Industrial Revolution. It gave rise to an unprecedented increase in productivity, intellectual activity and incomes. Because of limited space only selected topics are included. Here we see how dental literature developed and grew.

\section{MONTHLY REVIEW OF DENTAL SURGERY}

The British Dental Journal is now the dental journal with the longest continuous print-run in the United Kingdom. It makes this claim on the basis of incorporation in 1880 of

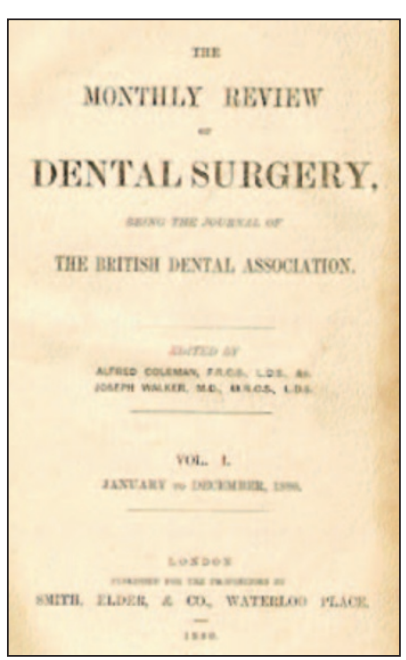

the Monthly Review of Dental Surgery as the Journal of the British Dental Association (Fig. 1). It was renamed British Dental Journal in 1903 but the title dates before then.

The Monthly Review was founded in 1872 as a rival to The Archives of Dentistry, which had appeared in 1864. The latter's editor was Edwin Truman of the Dental Hospital

Fig. 1 The cover of Volume 1, Number 1 of The Monthly Review of Dental Surgery 1880.

${ }^{1}$ Correspondence: to Professor Stanley Gelbier, Honorary Senior Research Fellow, Wellcome Trust Centre for the History of Medicine at University College London, 210 Euston Road, London, NW1 2BE

Email:s.gelbier@ucl.ac.uk

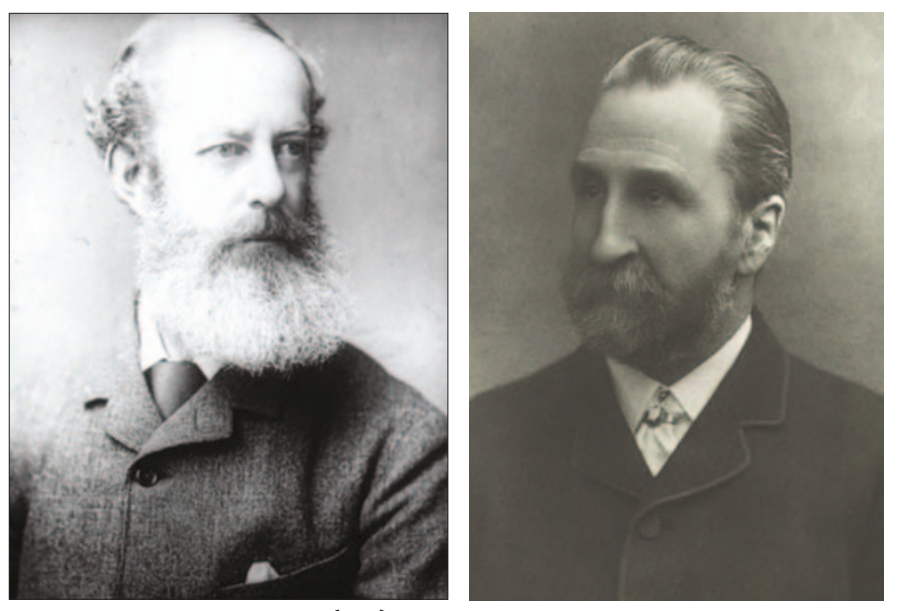

Figs 2 and 3 Alfred Coleman (left), who in 1880, together with Joseph Walker (right) edited The Monthly Review of Dental Surgery: Being the Journal of the British Dental Association

of London. The Monthly Review was edited by James Oakley Coles of the National Dental Hospital. In March 1880 the newly-formed BDA bought the Monthly Review and renamed it the Monthly Review of Dental Surgery: Being the Journal of the British Dental Association, edited by Alfred Coleman (Fig. 2) and Joseph Walker (Fig. 3). In 1903 it assumed the vacant British Dental Journal title, subtitled Journal of the British Dental Association.

The first issue of the Monthly Review ${ }^{1}$ stated: "Our object is to supply a want which has been urgently felt during late years, the want of an organ to adequately represent British Dental Surgery, to protect the interests of the Dental Profession, and to form a medium for the interchange of ideas between its individual members." The discussion of topics relating to dental surgery and dental mechanics was to occupy much space but there would be room for new theories, inventions and modes of practice plus reports from correspondents in European and American cities.

The first volume had 19 editorials, 37 original communications, notes from Germany, France and America, reports on materia medica, therapeutics and 15 new inventions. The last included 'Smale's nickel plating', 'Wood's mouth gag' and 'Elliott's dental burring engine', a "swiftly revolving burr or drill that will cut its way into the densest enamel or dentine with astonishing rapidity and with so little pain and annoyance that patients have 


\section{YEARS}

frequently expressed themselves highly delighted".2

The second issue indicated that the recent examination for the dental diploma of the Royal College of Surgeons of England was the first where students had a written paper as well as a viva. ${ }^{3}$ It suggested the curriculum was second only to that required for the main membership of the college. "In time, no doubt, the public will learn to discern between the qualified dental surgeon who holds the diploma of the College of Surgeons and the advertising charlatan, whose appeals to public credibility now fill the daily papers."

\section{MONTHLY REVIEW OF DENTAL SURGERY: JOURNAL OF THE BDA}

The 1880 volume dealt with death from chloroform, salivation and ethidine-trichloride (recently favoured on account of its agreeable flavour), nitrous oxide as an anaesthetic in dentistry, appointments of the three first dental professors to the new dental school at Queen's University, Belfast, a number of dental hospitals including Exeter, dentists' qualifications, the Society of Licentiates of Dental Surgery (formed to represent qualified dentists in Glasgow, claiming their faculty was more stringent than the English college).

W. H. Williamson produced home made nitrous oxide for general anaesthesia from granules of nitrate of ammonia at a cost of one penny per gallon. ${ }^{4}$ He claimed there was little danger from this anaesthetic but "in the case of weak and debilitated females" he first administered a teaspoonful of aromatic spirit of ammonia; and "it was rarely necessary to unlace corsets".

\section{THE BRITISH DENTAL JOURNAL}

The 1903 volume had 876 pages plus an educational supplement of 36 pages (Fig. 4). The latter indicated that the Royal Dental Hospital occupied a new building from 1901; and the National and Glasgow Dental Hospitals occupied recent buildings. It pointed out there were less dental students in 1902 (161) than in 1901 (186) or 1900 (174). The high point was 1895 (292). It suggested that unless the number was increased by foreign students and medical practitioners undergoing dental training the next

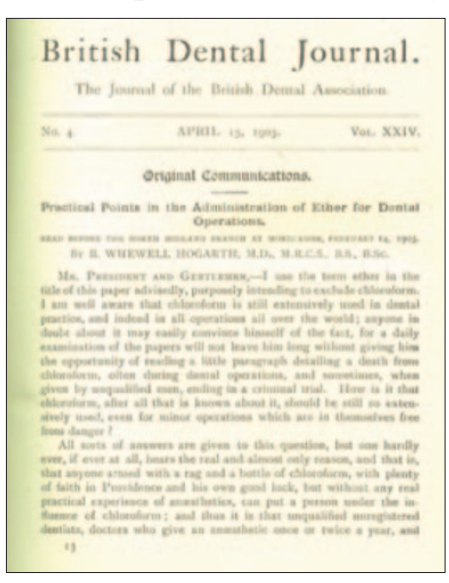

Fig. 4 The 1903 volume of The $B D J$ few years would be lean years as far as dental schools were concerned.

The journal assumed the new title in April. It carried pages of scientific and clinical content as well as advertisements. Looking ahead to the BDA conference it stressed that gentlemen wishing to avail themselves of the bowling green at Brighton Bowling Club should submit their names: a far cry from the modern golf competitions. There were original articles on the use of chloroform and ethyl chloride for dental operations. It carried part of an article by Willoughby D. Miller of Berlin on 'Introduction to the study of immunity in relation to the diseases of the mouth and teeth.5 A section on legal intelligence examined three court cases about the illegal use of dental titles, one in depth. ${ }^{6} \mathrm{~A}$ report indicated that soldiers of the Cheshire Regiment suffered from gastric and intestinal problems after eating tough and imperfectly chewed food because of many missing and decayed teeth. An order was placed for the immediate delivery of mincing machines to grind the food. ${ }^{7}$

\section{SOME OTHER 19TH CENTURY JOURNALS}

A number of other periodicals continued or first appeared in 1880 and beyond. The British Journal of Dental Science had been founded in July 1856 as a "monthly chronicle of current intelligence". It pointed out that most other groups in science, arts and the professions had a journal which provided a raised status. Published by John Churchill, in the first volume of 594 pages were papers on the properties and uses of gutta percha and aluminium. It described a new instrument; a vulcanised India-rubber ball into which was inserted a hollow 4-inch silver tube. Filled with water it washed cavities after caries removal. ${ }^{8}$ One fascinating correspondent said intercommunication would arouse in "the minds of professors of dentistry a spirit far higher than that of mere money". ${ }^{9}$ Recognising occasional problems in getting leeches to take hold, "especially in winter", the journal recommended a preliminary application of a "sinapism to induce vascular congestion, carefully washing the surface afterwards".10 The leeches then took freely with more bleeding than usual following their removal. An extract from the Medical Times on preventive dentistry suggested refined sugar from cane or beet is injurious to healthy teeth, "by immediate contact with these organs or by the gas developed while it is in the stomach". ${ }^{11}$ The British Journal of Dental Science was the official organ of the Odontological Society of Great Britain from 1863 to 1907 when the society merged with other groups to form the Royal Society of Medicine. It continued to appear until 1935.

The Dental Weekly only appeared between March and August 1895. Published by Billing and Company it contained major advertisements from the American Dental Manufacturing Company of Poland Street. Although claiming to be independent it hoped to see the BDA as a national association of all dentists.

The Weekly Dentist appeared in October 1898. In December it merged with The Dentist, a monthly which had appeared since January of that year. In September 1899 The Dentist was incorporated into the monthly British Dental Journal, which had been founded in 1898. From the third volume beginning 4 January 1900 it was 


\section{YEARS}

entitled the British Dental Journal and The Dentist. Within nine months it closed leaving the The $B D J$ title vacant.

The Dental Surgeon: a weekly review of dental science was published by Baillere, Tindall and Cox of London, in November 1904, edited by Robert Manning. His foreword claimed a need for a new weekly as "most dentists do not need as much as their medical colleagues"; perhaps "because there is not so much for them to read".

The Dental News was published from June 1909 as a weekly, concerned with "dentistry for dentists by dentists". Perhaps by then some dentists were getting tired of the more formal periodicals.

\section{THE DENTAL TRADE AND JOURNALS}

Some early periodicals disappeared before 1880. Most were devoted to dental politics as well as scientific matters. However, there was a vacuum for periodicals containing information about equipment and materials.

The dental manufacturers and retailers saw a niche to showcase their products to the profession. There was an important advance in 1881 when the Dental Manufacturing Company Limited produced The Dental Record: a monthly journal of dental science, art and literature devoted to the interests of the dental profession. Edited by Thomas Gaddes (Fig. 5) the journal was highly regarded by many practitioners. DMCo had been founded in 1873 by a group of English dentists as a cooperative. J. D. Crapper, a Manchester dentist, had the idea, invented the shares scheme and was the first managing director. Even before then he was selling porcelain teeth. It developed rapidly and soon had an extensive export trade selling

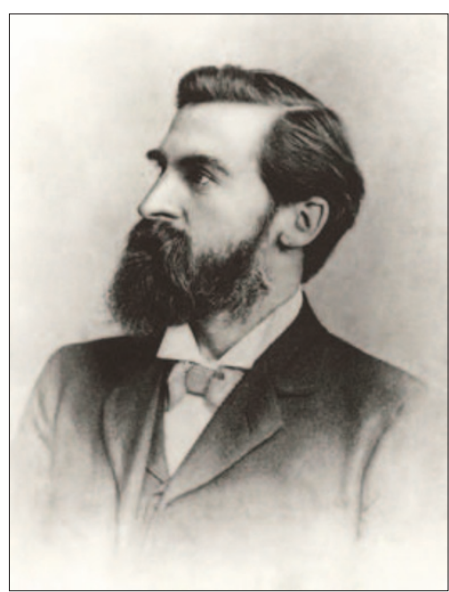

Fig. 5 Thomas Gaddes, Editor of The Dental Record: a monthly journal of an LDS, other qualifications dental science, art and literature being regarded as 'add-ons'. devoted to the interests of the dental being regarded as 'add-ons' profession, one of the first publications The journal soon found by a dental manufacturer. space for reports from smaller groups and societies, book reviews and correspondence columns. There were illustrations of new techniques and inventions in operative and mechanical dentistry. For example, one item of interest was that $\mathrm{M}$ Fauré had charged a box with electricity and sent it from Paris to Glasgow. In the 72 hours of transit a box of "condensed lightning" stored in a space of one cubit foot a power equivalent to "nearly a million of foot pounds". It was then used by Professor George Buchanan "to transmit its electricity through a platinum loop in order to remove a vascular tumour from the tongue of a boy; within a minute, with no loss of blood", a major advance. The Dental Record amalgamated with The Dental Practitioner in 1955.

The monthly Advertising Circular which appeared in July 1883 carried advertisements as well as abstracts from the British Journal of Dental Science which was produced by the same publisher. It closed at the end of 1884 .

In March 1885 Claudius Ash and Sons joined the fray by publishing the Quarterly Circular. Ash was possibly the first person to organise the British dental trade. As so often happens it started by chance. In 1820 he was a London silversmith. When delivering an item of decorative silverware to a dentist he was asked if he could copy a denture consisting of a set of teeth mounted on an 18 carat gold base, with gold springs and swivels. He then developed a business initially making dentures. The rest, as they say, is history. In some ways the Quarterly Circular consisted of a series of trade catalogues showing dentists the instruments the company produced. Importantly, it informed readers that the company was prepared to manufacture instruments based on sketches submitted by individual practitioners, a major service for the profession. As with a number of periodicals some material was extracted from other journals. However, the Quarterly Circular kept out of political and similar comment so there were no editorials. It grew and developed to become Ash's Quarterly Circular (19081910) and then Ash's Monthly (1911-1916). This was discontinued in 1916 as a result of conditions due to World War I but was replaced in January 1917 by Ash's Journal, renamed as the Dental Magazine in 1918. The latter was a major resource for the profession, bringing developments in practice to the notice of dentists.

In January 1921 the de Trey Company produced Oral Topics. Caesar de Trey came from Switzerland to London in 1901. By 1910 he brought from the USA the Solila Pin Tooth which replaced the more expensive platinum pin and was an immediate success. He acquired the sole European agency for Ritter equipment, then the world's largest manufacturer of dental equipment. He also sold Syntrex, one of the best known and widely sold silicate filling material which was made by his cousin. As a result he formed De Trey Freres. The first number of Oral Topics had many lessons appropriate for today's dentists and traders. Its editorial on 'Dentistry today and tomorrow' drew attention to the need for them to take account of the many changes going on around them. It pointed out that dentistry was no longer the prerogative of the rich. It was increasingly available to "the lowest as well as the highest" and was becoming recognised as "one of the 
most vital factors in the general well-being of humanity". The journal promoted the concept of an organised effort for dentistry as a factor in community welfare. Dental health education was not forgotten. It quoted Sir William Osler: "You have one gospel to preach, and have to preach it early and late, in season and out of season. It is the gospel of cleanliness of the mouth, cleanliness of the teeth, cleanliness of the throat."

De Trey combined with Claudius Ash in 1929 to form the Amalgamated Dental Company Limited, prompting a magazine merger to produce the Dental Magazine and Oral Topics. It made an important contribution, claiming eventually to reach 50,000 dentists and auxiliary staff in 30 countries. In 1970 it was absorbed into the British Dental Journal.

In 1876 Henry George Cottrell, a registered dentist, was making 'Fine Edge Gold Alloy' and selling other dental goods at Rodney Street in Liverpool. By 1888 business was so bad that Cottrell and Company of Liverpool ceased to exist. He left for London where he took the name Flint Edge Gold Alloy Company in 1896. In spite of some difficulties it lasted for a few years until he died. His sons Jack and Harry became a veterinary surgeon and dental surgeon, respectively. Surprisingly it was Jack who recommenced manufacture of the alloy. In 1896 he opened Cottrell and Company in Henrietta Street. Two years later Harry joined him after concluding his apprenticeship in dental mechanics, then still a route for entering dentistry. They divided up the United Kingdom to sell their wares on a personal basis. Their miniature dental depot was pushed from the station on a barrow, going from practice to practice. Cottrell's Dental Chronicle was published from1907 to 1910.

Some smaller journals were Elliott's Quarterly (1904-14) produced by Elliott and Company of Edinburgh, PCL Quarterly (1910-1915) from C. J. Plucknett and Company of London, Dental Delineator (1934-1969) from the S. S. White Company of Great Britain and Edward's Dental Quarterly (1912-15).

Although not directed towards the dental profession another important contribution from the trade was The Dental Trader. First published in 1973 its function was to educate and inform members of the trade. Any raised standards of production and sales have a clear advantage to dentists and the patients they treat.

\section{PUBLICATIONS OF SOCIETIES AND GROUPS}

In 1904 The Mouth Mirror was published by the Incorporated Dental Society. The Public Dental Services Gazette was published by the Public Dental Services Association from 1926, renamed Dental Gazette in 1934. Together with The Mouth Mirror it was incorporated into the $B D J$ in 1950, following merger of the BDA, PDSA and IDS. In 1994 the BDA produced BDJ Launchpad.

Although not strictly a journal, another publication worthy of note is The Transactions of the Odontological
Society of London. Begun in 1856 it continued in 1861 as The Transactions of the Odontological Society of Great Britain which also incorporated the Transactions of the College of Dentists (1857). It merged into the Transactions of the Royal Society of Medicine in 1907.

There were also Transactions of the School Dentists Society (1898-1920) and Transactions of the British Society for the Study of Orthodontics (1908-71). Orthodontists were also well served by The Orthodontist (1969-72), British Journal Orthodontics (sponsored by the BSSO and British Association of Orthodontists 1973-2000) and the Journal of Orthodontics (2000).

A number of other specialist societies published their own periodicals: British Journal Oral and Maxillofacial Surgery (1963), Community Dental Health (1984), Dental Health (1962), Dental Historian (1962), British Dental Surgery Assistant (1946-94) became British Dental Nurses' Journal (1994), Gerodontology (1982), Journal British Endodontic Society (1967-79), Journal British Society Dentistry for the Handicapped (1984-90) became Journal of Disability and Oral Health (2000), Proceedings British Paedodontic Society (1971-84) became Journal of Paediatric Dentistry (1985-90) and then International Journal of Paediatric Dentistry (1991). There were also the Proceedings of the British Societies for the Study Prosthetic Dentistry (1955), of Dental and Maxillofacial Radiology (1977-91) and of Periodontology (1951-69).

The Royal Dental Hospital Magazine (1924-64) was an early example of a journal produced by a single dental hospital. Primary Dental Care (1994) comes from the Faculty of General Dental Practice at the Royal College of Surgeons of England. Dental Update appeared from 1973. The Probe was published by the General Dental Practitioners' Association in 1959, describing itself as an independent newspaper for the dental team. Dental Practice (1969) and The General Dental Practitioner (1988) are publications providing a spread of information and news, the latter replacing the General Dental Practitioner Newsletter. The Ivory Cross Journal (1926-48) was produced by Gibbs as an early method of communicating dental health messages to children.

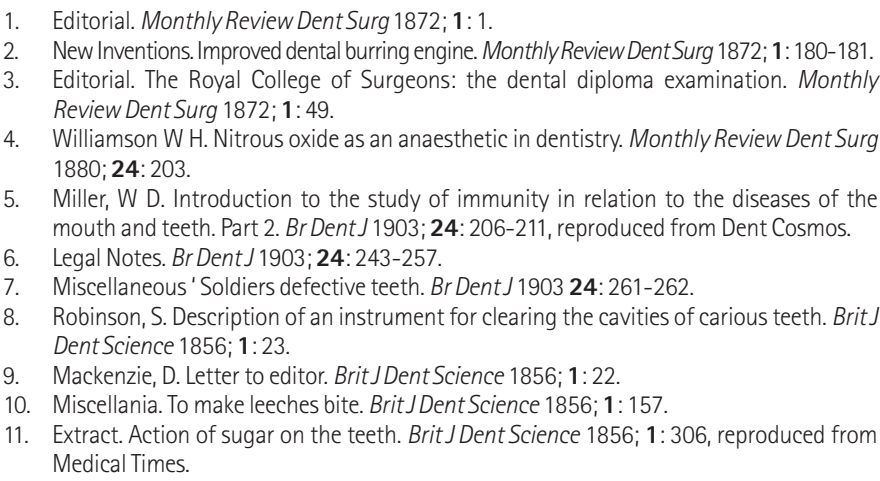

Williamson W H. Nitrous oxide as an anaesthetic in dentistry. Monthly Review Dent Surg 1880; 24: 203.

Miller, W D. Introduction to the study of immunity in relation to the diseases of the mouth and teeth. Part 2. Br Dent J 1903; 24: 206-211, reproduced from Dent Cosmos. Legal Notes. BrDent J 1903; 24: 243-257.

Miscellaneous ' Soldiers defective teeth. Br DentJ 1903 24: 261-262.

Robinson, S. Description of an instrument for clearing the cavities of carious teeth. Brit Dent Science 1856; 1: 23.

Mackenzie, D. Letter to editor. Brit J Dent Science 1856; 1:22.

10. Miscellania. To make leeches bite. Brit J Dent Science 1856; 1: 157

11. Extract. Action of sugar on the teeth. Brit J Dent Science 1856; 1: 306, reproduced from Medical Times. 